F. Reprod. Fert. (1966) 12, 139-144

\title{
COMPOSITION OF BULL EPIDIDYMAL AND TESTICULAR FLUID
}

\author{
R. G. WALES, J. G. WALLAGE AND I. G. WHITE \\ Department of Veterinary Physiology, University of Sydney, \\ Sydney, N.S.W., Australia \\ (Received 24th Fune 1965, finalized 8th November 1965)
}

\begin{abstract}
Summary. Analyses were made of fluid collected from the rete testis and the caput, corpus and cauda epididymidis of the bull. Both the major electrolytes and some organic constituents in the fluids were examined. There was a decrease in sodium and chloride as the fluid passed from the testis through the epididymis and at the same time there was a general increase in organic constituents. In testicular fluid, sodium and chloride made up the bulk of the ions present. In the epididymis, however, potassium replaced approximately half of the sodium and at the same time there was a general decrease in total electrolytes. Of the organic constituents, orcinol-reactive carbohydrate, protein and acidsoluble phosphorus, especially glycerylphosphorylcholine, were present in much higher concentrations in the epididymal than in the testicular fluid. Although little reducing sugar was found, lactic acid was present in all the fluids examined.
\end{abstract}

\section{INTRODUCTION}

Recently, Scott, Wales, Wallace \& White (1963) presented the results of chemical analyses made on fluid from the testis, caput epididymidis, cauda epididymidis and the vas deferens of the ram. Except for the reports by Salisbury \& Cragle (1956), Sorensen \& Andersen (1956) Cragle, Salisbury \& Muntz (1958) and of Crabo \& Gustafsson (1964) on the distribution of minerals in the reproductive fluids of the bull, little is known concerning the testicular and epididymal environment in this animal. Therefore, analyses have been made of fluid collected from the rete testis and from the caput, corpus and cauda epididymidis of the bull.

\section{MATERIALS AND METHODS}

Testes and epididymides were collected from bulls of mixed breed immediately after slaughter and packed in ice during transport to the laboratory. Testicular fluid was collected after severing the outlet to the caput epididymidis. The contents of the caput were obtained by gently scraping the cut surface to collect the tubular fluid which welled up. This fluid is equivalent to a mixture of the fluids collected from areas B, C and D designated by Crabo \& Gustafsson (1964). To collect fluid from the corpus epididymidis, the entire length of the 
mid-section of the epididymis was incised and fluid harvested by gently scraping the cut surface. Small incisions were made into the tubules of the cauda epididymidis and fluid squeezed out. The fluid obtained from the cut surface of the caput and corpus epididymidis is probably contaminated to a slight extent with tissue fluid. However, precautions were taken to see that this was kept at a minimum, and few blood cells were observed microscopically in uncentrifuged preparations. Fluid was pooled from ten to fifteen bulls for each replicate and centrifuged for $20 \mathrm{~min}$ at $18,000 \mathrm{~g}$ to remove cellular material. The supernatant, if not used immediately, was stored at $-35^{\circ} \mathrm{C}$.

In general, the analytical techniques used were similar to those reported previously (Scott et al., 1963). However, chloride was determined colorimetrically (Schoenfeld \& Lewellen, 1964). A recovery of $97 \pm 1 \%$ was obtained for chloride added to bull seminal plasma and assayed by this method. Bicarbonate was measured by back titration after liberation of all carbon dioxide with excess acid (Van Slyke, 1922). Where necessary, protein-free extracts were prepared by precipitation with barium hydroxide and zinc sulphate. Aliquots of protein-free extracts were chromatographed in a descending system with isopropanol-acetic acid-water $(3: 1: 1)$ as solvent and the resulting chromatogram developed for the detection of reducing sugars by oxidation with ammoniacal silver nitrate (Trevelyan, Procter \& Harrison, 1950).

Where possible, fluids from each region of the same groups of testes and epididymides were analysed for any one constituent. When insufficient fluid was available for this to be done, analyses of each region were performed on different batches of fluid as indicated in the tables. In some instances, analyses were also made of seminal plasma for comparison. The semen for lactate estimations was collected by an artificial vagina into sodium fluoride to inhibit the conversion of seminal fructose to lactic acid by the spermatozoa. All results are presented as means \pm the standard error (S.E.). In order to display the relative magnitudes and interrelations of the electrolytes, their values have been expressed in m-equiv/l (see Gamble, 1954). The valency of the phosphate ion has been taken as 1.8 (Gamble, 1954) and that of the citrate ion as 2.7 (Rothschild \& Barnes, 1954).

\section{RESULTS}

The results for analyses of testicular and epididymal fluids are summarized in Table 1. In the rete testis, the concentration of sodium ions was twice that in the caput epididymidis and there was a further, though less marked, decrease in sodium content in the corpus and cauda epididymidis. On the other hand, potassium values were lowest in the testicular fluid, rose in the caput and cauda epididymidis and fell again in the cauda region. As a result of these changes in the distribution of sodium and potassium, the sodium to potassium ratio changed from about 9:1 in the testis to a little over 1:1 in the caput epididymidis, and remained near unity in the other two regions.

There was also a decrease in the concentration of chloride ions in passing from the testis to the cauda epididymidis. This decrease was not as great as the fall in sodium ions and in each region the chloride concentration nearly balanced the sum of sodium plus potassium ions. In testicular fluid, sodium and 


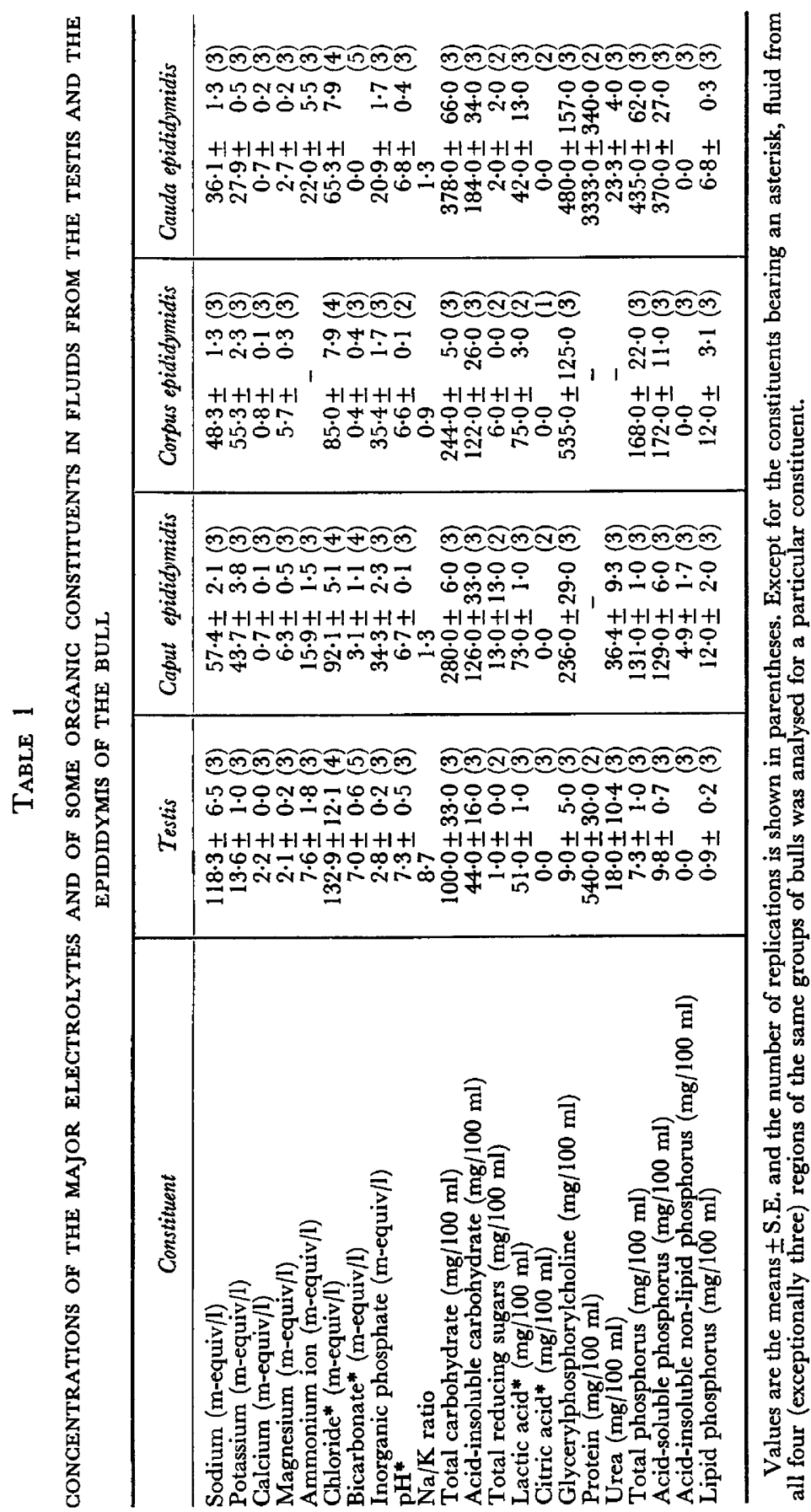


chloride were the major ions present and the electrolyte concentration was approximately equivalent to a relative tonicity of $100 \%$ when compared with $0.9 \%$ sodium chloride. In the epididymis, the electrolyte content was lower and in the cauda epididymidis there was only two-thirds the concentration found in testicular fluid.

The relationship between the acid and alkaline equivalents in the fluids is shown in Text-fig. 1. There was close acid-base equivalence in the testis and in the caput, corpus and cauda epididymidis.

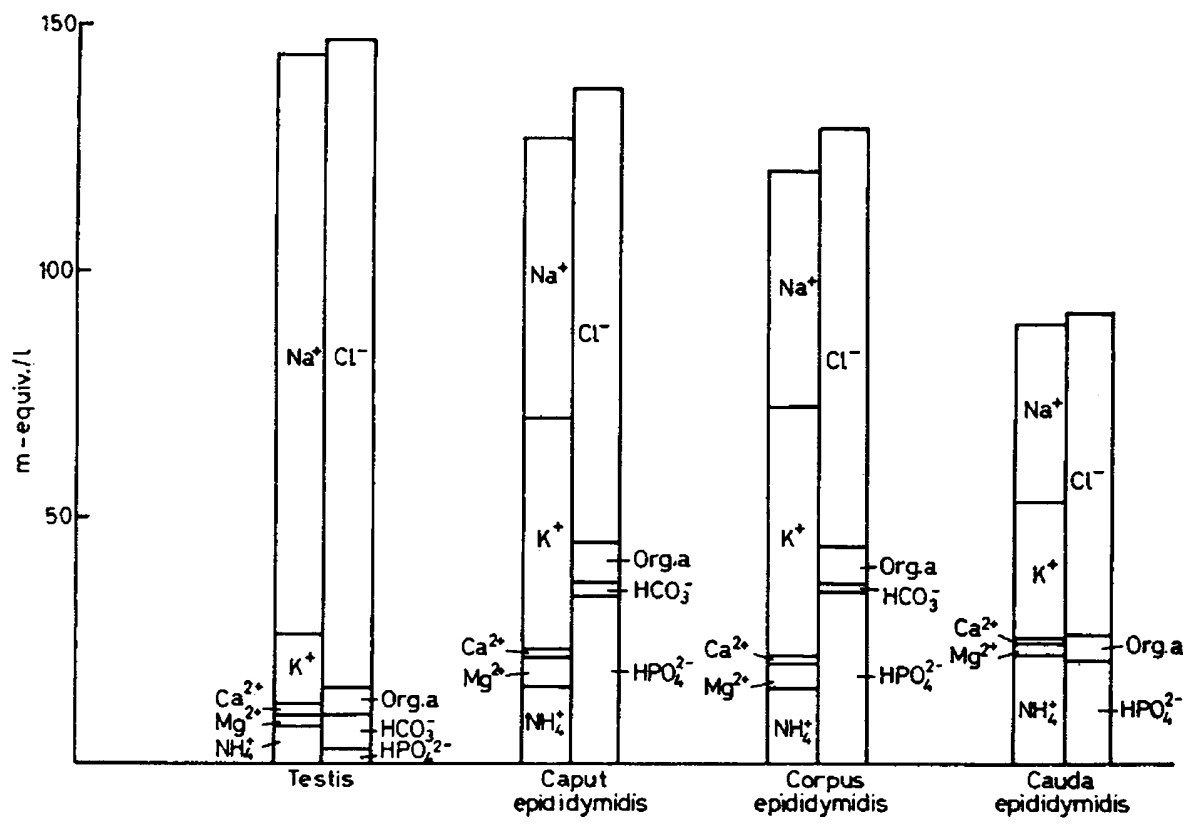

TEXT-FIG. 1. Relation between the acid and alkaline equivalents in testicular and epididymal fluid of bulls.

The results of analyses of organic constituents in fluids from the testis and epididymis showed that, in general, there was a greater concentration of organic constituents in the epididymis than in the testis and the highest content was found in the cauda epididymidis. Although little reducing sugar and no citric acid were present, there was an appreciable quantity of lactic acid in all the fluids. The high level of total phosphorus in the epididymal fluids compared with that in testicular fluid was due to an increase in acid-soluble phosphorus compounds, especially glycerylphosphorylcholine.

The results of analyses of bull seminal plasma are summarized in Table 2. The anions estimated amounted to $187 \mathrm{~m}$-equiv/l, of which the greater part was citrate. There was little lactic acid present in the seminal plasma and the concentration of ammonia was similar to that found in the epididymal fluid.

Chromatography of the testicular and epididymal fluids revealed a reducing substance with a $R_{F}$ of 0.20 to 0.24 in the system used. This substance appeared to be present in higher concentrations in the caput and cauda epididymidis than in testicular fluid, seminal plasma or fluid from the cauda epididymidis. 


\section{DISCUSSION}

Although the divisions of the epididymis in the present study are not identical with those designated by Crabo \& Gustafsson (1964) in their investigation of sodium and potassium distribution, the results, in general, are similar, especially with respect to potassium. There is also general agreement with the results of Scott et al. (1963) for ram epididymal plasma. However, the values obtained in the present study are not directly comparable with those of Salisbury \& Cragle (1956), since their analyses were performed on whole fluid and not on spermatozoa-free plasma.

The fall in the concentration of sodium and chloride as fluid passes down the epididymal duct has also been shown to occur in the epididymis of the ram (Scott $e$ al., 1963) and may well be a feature common to all mammalian epididymides. In the comparison of the total acid and alkaline equivalents in the fluids, the chloride concentration approximately balanced sodium plus potassium in all parts of the tract.

\section{TABLE 2}

CONCENTRATION OF SOME GONSTITUENTS IN THE SEMINAL PLASMA OF THE BULL

\begin{tabular}{l|r}
\hline \multicolumn{1}{c|}{ Constituent } & \multicolumn{1}{c}{ Mean \pm S.E. } \\
\hline Chloride (m-equiv/l) & $60 \cdot 0 \pm 5 \cdot 0(3)$ \\
Bicarbonate (m-equiv/l) & $12 \cdot 4 \pm 2 \cdot 2(3)$ \\
Inorganic phosphorus (m-equiv/l) & $8 \cdot 7 \pm 1 \cdot 6(2)$ \\
Citric acid m-equiv/l) & $84 \cdot 8 \pm 24 \cdot 0(3)$ \\
Ammonia (m-equiv/l) & $19 \cdot 5 \pm 1 \cdot 0(6)$ \\
Urea (mg/100 ml) & $46 \cdot 8 \pm 6 \cdot 0(5)$ \\
Lactic acid (mg/100 ml) & $2 \cdot 0 \pm 0 \cdot 6(3)$ \\
\hline
\end{tabular}

Values are the means \pm S.E. and the number of replicates is given in parentheses.

The high concentration of organic constituents and the low concentration of sodium and chloride ions in the cauda epididymidis, compared with testicular fluid, suggest that the cells of the epididymis actively secrete organic material into the lumen, and at the same time absorb sodium chloride. Some of the increase in the concentration of organic constituents may be due to the movement of water into the blood stream during the resorption of inorganic ions. As pointed out by Scott et al. (1963), there are a number of similarities between the tubules of the epididymis and the kidney. Both Nicander (1958) and Crabo \& Gustafsson (1964) have found an increase in spermatozoal density in the epididymis, presumably due to the resorption of fluid from the tubules.

The rise in acid-soluble phosphorus on passing from the testis to the cauda epididymidis may be accounted for in part by increasing levels of glycerylphosphorylcholine. This compound does not account completely for the change and another acid-soluble organic phosphate compound must appear in increasing concentration in the epididymis. As the organic constituents increase in concentration in the epididymis, there is a decrease in sodium chloride content which helps to maintain the osmotic pressure of the fluid within physiological limits. 
As found in the ram (Scott et al., 1963), there is a high level of lactate in the epididymal plasma of the bull. Its concentration is higher in the epididymis than in seminal plasma, presumably due to dilution of the epididymal plasma with accessory secretions during ejaculation. This lactate could act as a substrate for the spermatozoa, as it is readily metabolized under aerobic conditions and the results of Cross \& Silver (1962) indicate that conditions in the tubules may be aerobic.

At ejaculation, there are rapid and marked changes in the electrolyte environment of bull spermatozoa. In the cauda epididymidis, the plasma is citrate-free, chloride is the main anion and the sodium to potassium ratio is approximately unity. During ejaculation, accessory secretions are added to the epididymal contents, citrate becomes the predominant anion and the sodium to potassium ratio increases (Sorensen \& Andersen, 1956; Quinn, White \& Wirrick, 1965). The precise effect that these rapid changes in electrolyte environment have on the spermatozoa is not well understood, but they may account for some of the reported differences between ejaculated and epididymal spermatozoa.

\section{ACKNOWLEDGMENTS}

The authors are indebted to Professor C. W. Emmens for his interest and advice and to Mr P. Bryden of the New South Wales State Abattoirs, Homebush, for the collection of the bull testes. This work has been aided by grants from the Rural Credits Development Fund of the Commonwealth Bank of Australia, the Australian Dairy Produce Board, the Ford Foundation and the Lalor Foundation. One of us (J.C.W.) was supported by a Commonwealth Post-graduate Studentship.

\section{REFERENCES}

CRABo, B. \& Gustafsson, B. (1964) Distribution of sodium and potassium and its relation to sperm concentration in the epididymal plasma of the bull. $\mathcal{F}$. Reprod. Fert. 7, 337.

Gragle, R. G., Salisbury, G. W. \& Muntz, J. H. (1958) Distribution of bulk and trace minerals in bull reproductive fluids and semen. 7. Dairy Sci. 41, 1273.

CRoss, B. A. \& Silver, I. A. (1962) Neurovascular control of oxygen tension in the testis and epididymis. 7. Reprod. Fert. 3, 377.

Gamble, J. L. (1954) Chemical anatomy, physiology and pathology of extracellular fluid. Harvard University Press, Cambridge, Massachusetts.

NIGANDER, L. (1958) Studies on the regional histology and cytochemistry of the ductus epididymidis in stallions, rams and bulls. Acta morph. neerl. scand. 1, 337.

Qunn, P. J., White, I. G. \& WrRrick, B. R. (1965) Studies of the distribution of the major cations in semen and male accessory secretions. J. Reprod. Fert. 10, 379.

RothsGHILD, LORD \& BARNes, H. (1954) Constituents of bull seminal plasma. F. exp. Biol. 31, 561.

SAlisbury, G. W. \& GRAGLe, R. G. (1956) Freezing point depressions and mineral levels of fluids of the ruminant male reproductive tract. Proc. IIIrd int. Congr. Anim. Reprod., Cambridge, p. 25.

Schoenfeld, R. G. \& LewEllen, C. J. (1964) A colorimetric method for determination of serum chloride. Clin. Chem. 10, 533.

Scott, T. W., Wales, R. G., Wallace, J. C. \& White, I. G. (1963) Composition of ram epididymal and testicular fluid and the biosynthesis of glycerylphosphorylcholine by the rabbit epididymis. 7. Reprod. Fert. 6, 49.

Sorensen, E. \& ANDERsen, S. (1956) The influence of sodium and potassium ions upon the motility of sperm cells. Proc. IIIrd int. Congr. Anim. Reprod., Cambridge, p. 45.

Trevelyan, W. E., Procter, D. P. \& Harrison, J. S. (1950) Detection of sugars on paper chromatograms. Nature, Lond. 166, 444.

VAN SLYKe, D. D. (1922) Studies of acidosis. 18. Determination of bicarbonate concentration of the blood and plasma. 7. biol. Chem. 52, 495. 